\title{
GAMBARAN TEKAN INTRAOKULAR PADA PEMAIN MUSIK BIA
}

\author{
${ }^{1}$ Junior Pratasik \\ ${ }^{2}$ Nancy Engka \\ ${ }^{2}$ Siantan Supit \\ ${ }^{1}$ Kandidat skripsi Fakultas Kedokteran Universitas Sam Ratulangi Manado \\ ${ }^{2}$ Bagian Fisologi Fakultas Kedokteran Universitas Sam Ratulangi Manado \\ Email: gabbse24991@yahoo.com
}

\begin{abstract}
Intraocullar Pressure (IOP)closely related to Glaukoma,the 2nd Indonesian blindness causes. Ophtalmology's riset aproximately during 10 years found an association inflatable music play and increased of IOP. One kind of inflatable music in North Sulawesi which known as Musik Bia (sea shell wind instrument) who had recently recorded in Guiness World Book Of Record as The Biggest Sea Shell Wind Instrument Ensemble. Scientific evidence and fact above have placed inflatable music player especially Bia Music player particularly into high - risk groups of Glaucoma disease This Study aims to reveal the IOP on Bia music player From Batu Villages.Research was done by using cross sectional design. Sample amounted 27 player have fulfilled inclusion criteria that were $11-70$ years old, physically and mentally healthy, are more than 6 months playing music, be willing to sample and signed the informed consent. The instrument used is the Non - Contack Tonometer. The results of observation shows that The mean IOP in male player is $12.16 \mathrm{mmHg}$ in the right eye and the left eye is worth $12,35 \mathrm{mmHg}$, whereas the average of IOP in female player is $10.32 \mathrm{mmHg}$ in the right eye and left eye iop mean value is $10.42 \mathrm{mmHg}$. In 27 bia music player consisting of 23 men and 4 woman had a mean IOP are generallynormal.
\end{abstract}

Keywords: Intraocular Pressure (IOP),Bia Music Player

\begin{abstract}
Abstrak: Tekanan intraokularerat kaitannya dengan penyakit glaukoma yang menjadi penyabab kebutaan kedua di Indonesia. Penelitian dalam dunia Opthalmology kurang lebih 10 tahun terakhir menemukan adanya hubungan bermain musik tiup dan peningkatan tekanan intraokular Salah satu jenis musik tiup di Sulawesi Utara adalah musik bia yang tercatat pada Guiness World Book Of Record sebagai the biggest sea shell music ensemble orchestra.Bukti ilmiah dan fakta diatas menempatkan pemain musik bia kedalam kelompok resiko tinggi penyakit Glaukoma Penelitian ini bertujuan untuk mengetahui gambaran tekanan intraokular pada pemain musik bia di desa Batu.Penelitian ini menggunakan rancangan penelitian cross sectional.Sampel penelitian berjumlah 27 pemain yang telah memenuhi kriteria inklusi yaitu berumur 11-70tahun, sehat jasmani dan rohani, sudah lebih dari 6 bulan memainkan musik, bersedia dijadikan sampel penelitian dan menandatangani informed consent. Alat yang digunakan adalah tonometer non - kontak. Hasil pengamatan menunjukan rerata tekanan intraokular mata kanan pada pemain pria sebesar 12,16 mmHg dan pada mata kiri bernilai 12,35 mmHg, sedangkan pada pemain wanita rerata tekanan intraokular sebesar 10,32 mmHg pada mata kanan dan rerata tekanan intraokular mata kiri bernilai 10,42 mmHg.Pada 27 orang pemain musik bia yang terdiri dari 23 pria dan 4 wanita memiliki rerata tekanan intraokular umumnya normal.
\end{abstract}

Kata Kunci: Tekanan Intraokular,Pemain Musik Bia. 

Salah satu faktor yang perlu diwaspadai dalam hubungannya dengan kesehatan mata adalah peningkatan tekanan intraokular.Peningkatan tekanan intraokular sen diri erat kaitannya dengan penayakit Glaucoma yang merupakan penyebab kebutaan kedua terbanyak setelah katarak di Indonesia. Penyakit ini menyebabkan kerusakan perlahan pada saraf optik sehingga penderita seperti tanpa keluhan yang mengakibatkan keterlambatan dalam diagnosa (1-4).

Nilai tekanan intraokular pada setiap individu dipengaruhi oleh beberapa faktor antara lain: usia, jenis kelamin, musim, variasi diurnal, ras , obat obat anastesi, alkohol. Mandang dalam penelitiannya tentang Perbandingan Glaucoma pada Golongan Orang Minahasa yang Diam di Urban dan Rural area menunjukan tekanan intraokular pada masyarakat Minahasa yang diam di desa (rural area) lebih rendah dari yang diam di kota(Urban Area)(1, 2, 5-7).

Musik tradisional sebagai sarana hiburan. Salah satu contohnya adalah alat musik yang berasal dari kerang laut yang dikenal dengan musik bia yang belum lama ini mencatatkan tinta emas sebagai the biggest sea shell musik ensemble orchestra dalam Guinness World Record pada tahun 2010 yang lalu. Media Indonesia melaporkan di Sulawesi Utara dalam usaha pemecahan rekor dunia Guinesss, terdapat 339 peniup alat musik Bia dengan usia termuda 6 Tahun dan yang tertua 80 Tahun $(1,8-11)$.

Penelitian di dunia Opthalmology selama kurang lebih 10 tahun terakhir menemukan bahwa adanya hubungan antara bermain musik tiup (wind instrument) dengan tekanan intraokular. Tekanan intraokular didapati meningkat sementara (transient increased) pada pemain musik tiup, sementara dan sesudah mereka memainkan musik dengan durasi bermain selama 10 menit.Penelitian ini menyimpulkanbahwa para pemain musik tiup adalah kelompok resiko tinggi terhadap Glaucoma yang perlu untuk dimonitoring (13-17) Adanya penelitian diatas secara langsung memasukan pemain musik bia sebagai kelompok resiko tinggi. Fenomena ini ditambah dengan belum adanya literatur yang memadai tentang tekanan intraokular dan musik bia (sea shell wind instrument) di Sulawesi Utara khususnya, menjadi alasan penulis ingin meneliti hal tersebut lebih jauh.

\section{METODE PENELITIAN}

Penelitian ini bersifat observasional dengan menggunakan pendekatan cross sectional untuk mengetahui karakteristik serta gambaran tekanan intraokular pada pemain musik bia Mutiara Laut. Penelitian ini mengambil tempat di Balai Kesehatan Mata Masyarakat kota Manado Provinsi Sulawesi Utara padabulan Desember 2012. Populasi penelitian adalah kelompok pemain musik tiup yang tinggal di desa Batu, Kecamatan Likupang Selatan, Kabupaten Minahasa Utara. Sampel penelitian adalah Bagian dari populasi kelompok pemain musik tiup di desa Batu dengan jumlah minimal 30 orang yang memenuhi kriteria inklusi berusia 11 - 70 tahun, sehat jasmani dan rohani, dan besedia dijadikan sampel penelitian. Instrumen yang digunakan dalam penelitian adalah tonometer non kontak, manset, stetoskop dan alat tulis. Pekaksanaan penelitian diawali dengan proses persiapan berupa permohonan izin kepada pemilik grup dan Kepala BKMM, penandatangan informed consent dan penjelasan seputar pemeriksaan dan cara kerja alat.

Pengambilan data dilakukan dengan cara mewawancarai para pasien dengan beberapa pertanyaan kemudian dilakukan pemeriksaan tekanan intraokular dengan menggunakan tonometer non - kontak dan diakhiri oleh pemeriksaan tekanan darah. Data yang diperoleh kemudian dikumpulkan dan diolah untuk mendapatkan karakteristik dan gambaran tekanan intraokular pada pemain musik bia yang kemudian disajikan dalam bentuk tabel distribusi frekuensi. 


\section{HASIL PENELITIAN PEMBAHASAN}

Penelitian ini mencatat sebanyak 27 orang pemain musik bia yang ikut serta terdiri dari 23 orang laki - laki $(85,2 \%)$ dan
DAN 4 orang wanita (14,8\%), dengan kelompok umur 31 - 40 tahun yang terbanyak (33,3\%). Hasil dari wawancara mencatat kelompoklamanya menjadi pemain terbanyak ialah yang telah bermain sekitar 1 - 5 tahun (51,9\%).

Tabel 1. Distribusi frekuensi subyek berdasarkan alat musik

\begin{tabular}{lcc}
\hline Alat Musik & $\mathrm{N}$ & $\%$ \\
\hline Bass & 2 & 7.4 \\
Biak & 6 & 22.2 \\
Biak sambung & 1 & 3.7 \\
Do & 1 & 3.7 \\
Do-re-mi & 1 & 3.7 \\
Korno & 1 & 3.7 \\
Re-mi-fa & 6 & 22.2 \\
Saxophone & 3 & 11.1 \\
Si-do & 2 & 7.4 \\
Si-do-re & 1 & 3.7 \\
Sol kecil & 1 & 3.7 \\
Sol tengah & 2 & 7.4 \\
\hline Jumlah & 27 & $100 \%$ \\
\hline
\end{tabular}

Sumber: Data primer

Distribusi frekuensi subyek berdasarkan alat musik pada tabel 1 menunjukan bahwa alat musik yang

digunakan bervariasi tetapi yang terbanyak adalah bia re - mi - fa dan Biak maisng masing sebesar 22,2 \%.

Tabel 2. Rerata tekanan intraokular kedua mata berdasarkan jenis kelamin

\begin{tabular}{|c|c|c|c|c|}
\hline \multirow[t]{2}{*}{ Jenis Kelamin } & \multirow[t]{2}{*}{$\mathrm{n}$} & \multirow[t]{2}{*}{$\%$} & \multicolumn{2}{|c|}{$\begin{array}{l}\text { Nilai rata - rata tekanan intraocular } \\
(/ \mathrm{mmHg})\end{array}$} \\
\hline & & & TIOD & TIOS \\
\hline Laki - laki & 23 & 85.2 & 12,16 & 12,35 \\
\hline Perempuan & 4 & 14.8 & 10,32 & 10,42 \\
\hline Jumlah & 27 & $100 \%$ & & \\
\hline
\end{tabular}

Sumber: Data Primer

Rerata tekananan intraokular kedua mata berdasarkan jenis kelamin seperti terpampang pada tabel 2 menunjukan subyek laki - laki berjumlah 23 orang (85,2\%) dengan rerata tekanan intraokular mata kanan bernilai 12,16 $\mathrm{mmHg}$ dan rerata tekanan intraokular mata kiri bernilai
12,35 mmHg. Jumlah subyek wanita sebanyak 4 orang (14,8\%) dengan persentasi rerata tekanan intraokular mata kanan bernilai $10,32 \mathrm{mmHg}$ dan rerata tekanan intraokular mata kiri bernilai 10,42 mmHg. 
Tabel 3. Rerata - rata tekanan intraokular kedua mata berdasarkan kelompok umur

\begin{tabular}{|c|c|c|c|c|}
\hline \multirow{2}{*}{$\begin{array}{l}\text { Kelompok } \\
\text { Umur } \\
\text { (Tahun) }\end{array}$} & \multirow[t]{2}{*}{$\mathrm{n}$} & \multirow[t]{2}{*}{$\%$} & \multicolumn{2}{|c|}{$\begin{array}{l}\text { Nilai rata - rata tekanan intraokular } \\
(/ \mathrm{mmHg})\end{array}$} \\
\hline & & & TIOD & TIOS \\
\hline $11-20$ & 6 & 22,2 & 12,35 & 12,80 \\
\hline $21-30$ & 2 & 7,4 & 13,50 & 11,70 \\
\hline $31-40$ & 9 & 33,3 & 12,37 & 12,26 \\
\hline $41-50$ & 3 & 11,1 & 10,10 & 10,00 \\
\hline $51-60$ & 2 & 7,4 & 13,50 & 14,50 \\
\hline $60-70$ & 5 & 18,6 & 10,34 & 11,28 \\
\hline \multirow[t]{2}{*}{ Jumlah } & & & & \\
\hline & 27 & $100 \%$ & & \\
\hline
\end{tabular}

Sumber : Data Primer

Rerata tekanan intraokular menurut kelompok umur pada tabel 3 menunjukan kelompok umur 31 - 40 tahun sebagai yang terbanyak dengan frekuensi sebesar 9 orang(33,3\%) dimana tekanan intraokular pada masing mata adalah $12,37 \mathrm{mmHg}$ pada mata kanan dan 12,26 mmHg pada mata kiri.

Tabel 4. Rerata nilai tekanan intraokular kedua mata berdasarkan lamanya pemain

\begin{tabular}{cclccc}
\hline $\begin{array}{c}\text { Lamanya } \\
\text { menjadi pemain } \\
\text { (tahun) }\end{array}$ & $\mathrm{n}$ & $\%$ & \multicolumn{3}{c}{$\begin{array}{c}\text { Nilai rata - rata tekanan } \\
\text { intraokular } \\
(/ \mathrm{mmHg})\end{array}$} \\
\hline $1-5$ & 14 & 51,9 & TIOD & TIOS \\
$6-10$ & 2 & 7,4 & 11,01 & 12,80 \\
$11-15$ & 6 & 22,2 & 16,35 & 11,70 \\
$16-20$ & 2 & 7,4 & 12,60 & 12,26 \\
$21-25$ & 2 & 7,4 & 12,50 & 14,00 \\
$26-30$ & 1 & 3,7 & 11,50 & 11,28 \\
\hline Jumlah & 27 & $100 \%$ & 10,34 & \\
\hline
\end{tabular}

\section{Sumber : Data Primer}

Tabel 4 menunjukan kelompok umur 1-5 tahun yang paling banyak dengan frekuensi sebesar 14 orang (51,9\%) dengan nilai rata - rata tekanan intraokular pada kedua mata sebesar $11,1 \mathrm{mmHg}$ pada mata kanan dan 12,80 mmHg pada mata kiri.

Pada penelitian ini, alat musik tiup yang digunakan pemain memiliki hubungan dengan peningkatan tekanan intraokular. Hal ini didukung oleh penelitian dari Schmidtmann pada tahun 2011 di Jerman, yang melibatkan pemain musik brass dan woodwind dimana alat yang memiliki frekuensi nada tinggi, pemain musiknya memiliki tekanan intraokular yang lebih tinggi dari yang lain (13). Pada penelitian kali ini tidak diketahui pasti alat mana yang memiliki frekuensi nada tinggi dikarenakan belum ada studi lengkap mengenai alat musik ini.

Pada penelitian kali ini dijumpai rerata tekanan intraokular pada semua kelompok 
usia pemain musik bia adalah $\pm 10,00$ $\mathrm{mmHg}-12,00 \mathrm{mmHg}$ yang artinya dalam batas normal. Hasil ini selaras dengan penelitian yang dilakukan oleh Mandang pada tahun 1973 dimana masyarakat pedesaan (rural area) memiliki rata - rata tekanan intraokular yang lebih rendah dibandingkan masyarakat perkotaan (Urban Area) (1).Hal ini mungkin disebabkan oleh faktor - faktor lain dari subyek yang tidak diketahui seperti pola diet, aktivitas, ras, variasi diurnal, dan hormonal yang biasanya mempengaruhi fluktualisasi tekanan intraokular.

Penelitian yang dilakukan oleh Mandang pada tahun 1977 di Sulawesi Utara, menunjukan adanya hubungan antara tekanan intraokular dengan jenis kelamin, dimana wanita biasanya lebih tinggi dari pria (1). Hal ini biasanya dipengaruhi oleh faktor hormonal dimana pada kelompok usia menopause wanita memiliki tekanan intraokular lebih tinggi dari pria dikelompok usia yang sama (2). Pada penelitian kali ini didapat rerata tekanan intraokular pada kelompok wanita lebih rendah dari kelompok pria. Hal ini disebabkan oleh jumlah sampel wanita yang lebih sedikit dari pada pria.

Lamanya menjadi pemain musik tiup menjadi tolok ukur penting dalam penelitian ini sebab pada penelitian sebelumnya yang dilakukan oleh Schmidtmann pada tahun 2011 di Jerman. Pada penelitian inididapati hubungan antara bermain musik tiup dengan peningkatan tekanan intraokular. Hal ini terjadi karena pada saat meniup mengakibatkan peningkatan tekanan intrathorac dan kompresi pada sistem vena intrathorac, sesuai dengan teori bahwa peningkatan tekanan dan kompresi yang terjadi ditransmisikan melalui vena jugularis ke Choroid yang menyebabkan pelebaran pembuluh darah sehingga meningkatkan volume choroid dan meningkatkan tekanan intraokular.

Pada penelitian kali ini pada pemain musik biadidapati rerata tekanan intraokular normal. Hal ini disebabkan karena penelitian dilakukan tanpa intervensi/perlakuan sementara meniup alat, sehingga sangat direkomendasikan untuk diadakan penelitian lanjutan mengenai hubungan tekanan intraokular dengan bermain musik tiup dengan cara pengukuran sebelum, sementara dan sesudah bermain musik tiup untuk mengetahui seberapa besar peningkatan tekanan intraokular pada pemain musik bia ini sebelum, sementara dan sesudah bermain musik tiup.

\section{SIMPULAN}

Pada pemain musik bia "MUTIARA LAUT” dengan anggota 27 pemain yang terdiri

dari 23 pria dan 4 wanita memiliki rerata tekanan intraokular umumnya normal.

\section{UCAPAN TERIMA KASIH}

Ucapan terima kasih disampaikan pada dr. H. Polii, Mkes, AIFM sebagai penguji I dan dr. S. Marunduh, M.Med, AIFM sebagai penguji II, dan pada semua pihak baik secara langsug maupun tidak langsung telah menumbuhkan ide atau gagasan dalam pemikiran penulis sehingga dapat menyelesaikan artikel ini.

\section{DAFTAR PUSTAKA}

1. Mandang J H A. Penelitian perbandingan glaucoma pada golongan orang minahasa yang diam di urban dan rural area. [Dissertation].Universitas Sam Ratulangi;1977.

2. Zaldi, Perbedaan tekanan intraokuler pada pria dan wanita emetropia berusia 40 tahun atau lebih pada rumah sakit umum pusat haji adam malik dan rumah sakit umum daerah Dr. Pirngadi Medan, 2003, USU

3. Ilyas Sidarta, Glaukoma.Fakultas Kedokteran Universitas Indonesia.1977

4. Ilyas Sidarta, Ilmu penyakit mata. Edisi ketiga.Cetakan ke 8.Fakultas Kedokteran Universitas Indonesia. 2010.

5. adler, Textbook of ophthalmology $7^{\text {th }}$ ed.1962.P: 331.

6. Guyton A, Hall J. Textbook of medical physiology $11^{\text {th }}$ edition. Editor Edisi bahasa Indonesia : Rachman L Y, Hartanto 
H, Novrianti A, Wulandari N. Penerbit buku kedokteran.EGC.

7. Vaughan D G, Asbury Taylor , Riordan eva Paul. General Ophtalmology $13^{\text {th }}$ edition, a Lange Medical Book.. P : 213

8. Llobet A, Gasull X, Gual A. Understanding trabecular meshwork physiology : A Key to the control of intraocular pressure. Physiology.2003.18 : $205-209$

9. anonym. Pengaruh penambahan lubang terhadap frekuensi yang dihasilkan Kuli Bia.Universitas Kristen Satya Wacana. 2011.

10. Gloria S D, Hasugian J.Teori Musik. Diaksess pada : 25 Oktober 2012

11. Yusuf Renaldy. Perkembangan Musik Tradisional Indonesia.

12. Media Indonesia. Musik bia masuk buku guiness world records.2010. Available from http://www.indonesiamedia.com/2010/07/2 8/musik-bia-masuk-buku-guinness-worldrecords/. Diakses pada : 25 October 2012

13. Schimidtmann G, Jahnke S, Seidei EJ, Sickenberger W, Grein HJ. Intraocular pressure fluctuations in professional brass and woodwind musicians during common playing conditions. Department of Visions Sciences, Glasgow Caledonian University. Greefes Arch Clin Expo Ophthalmology 2011

14. Bakke E, Hisdal J, Semb S. Intraocullar pressure increases in parallel with systemic blood pressure during isometric exercise.2009. IOVS Vol.50. No.2 Page:

15. Khan JC, Hughes E H, TOM BD , Diamon J P. Pulsatile ocular blood flow : the effect of the valsava manoeuvre in open angel and normal tension glaucoma: case report and prospective study. $\mathrm{Br} \mathrm{J}$ ophthalmology 2002.86:1089-1092

16. Schuman JS, Maschiotte EC, Connolly S, Hertzmark E, Mukherji B, Kunen MZ. Increased intraocular pressure and visual field defect in high resistance wind instrument players. New England eye center, Tufts University School of medicine, Boston Massachusetts 0211,USA.2000. Available on :http://www.ncbi.nlm.nih.gov/pubmed/106 47731

17. Aydin P, Oram O, Akman A, Dursun D. effect of wind instrument playing on intraocular pressure. Department of Ophthalmology, Baskent University , School of Medicine, Ankara,Turkey. 2000. Available on: http://www.ncbi.nlm.nih.gov/pubmed/1095 8606? $\log \$=$ activity

18. Sarkisan S. An Up date On Tonometry.Glaucoma today.2006

19. Sumoro H. Frekuensi dasar, Harmonics, dan overtune. 2007

20. Steven S. How to measure intraocular pressure : Schiotz Tonometry 2008 